\title{
Analysis on China's Food Policy under Government Regulation
}

\author{
Wentan $\mathrm{Wu}^{1, \mathrm{a}}$ and Baoming $\mathrm{CaO}^{1}$ \\ ${ }^{1}$ Food Security and Strategic Research Center, Nanjing University of Finance and Economics, \\ Nanjing, Jiangsu, 210003 \\ awuwentan2008@163.com
}

Keywords: Government Regulation, Food Policy, Evolution Logic, Revelation

\begin{abstract}
Being a significant component of agriculture policy, food policy plays a considerable role in safeguarding food security in China. Analysis on the course the food policy evolves was made herein from the perspective of government regulations, that is how tough the regulations exercise and variation of objects under control, which proved that the evolution of the food policy has been in full accord with the change of China's macroeconomic system, the means the food policy employs is full in line with China's macroeconomic means. In implementation, the evolution of food policy is reflected in variation in objects, means and intensity of regulations.
\end{abstract}

\section{Introduction}

Food is a significant strategic commodity, holding the key to a nation's economy, politics and society. It is a general practice for the government to conduct necessary economic regulation on production, circulation and consumption that food chain goes through, in an effort to safeguard food security and maintain economic and social stability. To strike the pre-determined goal of food policy, the government shall, in the course of establishing and implementing the food policy, adjust and transform the policy in light of food supply and demand and the macroeconomic environment that are never cease to change. Therefore, the evolution course of food policy in itself embodies the process of food regulation that is in constant adjustment by the government in line with our ever-changing grain situation and our distinct conditions. It was attempting to study the evolution of food policy in China from the view of government regulation, discuss the internal logic the food policy pursues and summarize the law and experience of such evolution. This attempt is of great importance to further our food policy in the context of new food security.

\section{Analysis on evolution of China's food policy}

The strength on food control in different stages finds expression in food policies developed by China on objects regulated. Since the founding of P.R.C., the food policy can be divided into the following four stages under different strengths:

(I) Non-regulation from 1949 to 1952

In the early days of the new nation, we were confronted with a complicated domestic and international environment. Grain became especially important during that period as it was closely related to people's lives. Less control on food in this period was aimed at stimulating food production and ensuring sound circulation.

In production, the government brought up grain procurement price while engaging in land reform; in circulation, the government practiced free procurement and marketing. While capitalizing on and imposing limit and reform on private grains, the government was strengthening the state grains to be the market leader. During this period, a whole range of grain management 
system was developed with Ministry of Food established. It also set great store by grain reserves, contributing to national grain reserves. In consumption, the government supplied the grain reserves to the market when food shortage occurred, in a bid to allow people accessing to food.

(II) Strengthened regulation from 1953 to 1957

From 1953 onwards, we implemented the planned economy in the field of economy. To facilitate the socialist construction, we gave priority to the development of heavy industry and adopted the policy of "state monopoly for purchases and marketing" in food sector, imposing stricter regulation on grain.

In production, the planned procurement price was determined as the quoted price at that time. The unified procurement price was approximately equal to the market price. This period witnessed no dramatic price change. In circulation, the practice of the policy of "state monopoly for purchases and marketing" made it tighter on grain market. Meanwhile, it carried out the grain management system with the central government as the general commander and the central government and local governments taking their due parts in management. It allowed exporting some of grains in return for foreign exchange so as to fund the socialist construction and industrialization. In consumption, the urban residents and rural people shoring of grains were supplied in a planned manner, which restricted grain consumption to some extent.

(III) Overall regulation from 1958 to 1978

The grave erroneous path of rural economy during this period tremendously discouraged farmers from engaging in grain. Consequently, grain output was slashed substantially, straining food supply. In such circumstance, the government strengthened control in grain sector.

With regard to production, the procurement price had been increased frequently to boost farmers' enthusiasm in farming. The period from 1958 to 1966 had seen the procurement price brought up in five times. It continued to pursue the policy of "state monopoly for purchases and marketing” in circulation. The grain management system had gone from decentralization to centralization of the central and local governments, contributing to the final system featuring highly centralized "four centralizations" in 1972. What is more, some of grains had been imported to ensure adequate food supply. At the same time, a considerable amount of grains had been reserved for the nation and society. In terms of consumption, the government was constantly increasing the price of unified marketing on one hand, and lowered the food standards of urban residents, providing food subsidies to urban employees.

(IV) Loose regulation from 1979 to now

In December 1978, the convening of the Third Plenary Session of the 11th Central Committee of the Communist Party of China marked the beginning of our economic system reform. With the market-oriented reform moving further, the government was gradually lifting its overall control on grain under planned economy in a rational order.

With regard to production, the government was constantly boosting the procurement price, while giving more subsidies in production and income to farmers. In circulation, the first step was loosening control on grain procurement. For this purpose, in 1985, the system of "unified purchasing of farm produce by the state according to fixed quotes" was superseded by the "dual-track system", which in fact legitimized free market trading. The year of 2004 saw fully liberation of food procurement. Secondly, the grain management system was implemented by the central and low authorities in their granted power with provincial governors accountable for food security. Furthermore, it strengthened market-oriented reform of state-owned grain enterprises and brought about a whole range of grain reserve system. The liberation on consumption was 
represented by increase in sale price, abolishment of planned supply and complete market-driven consumption. In the second half of 1993, grain coupons and unified sales were basically out of sight. There was also food aid to low-income groups.

\section{Internal Logic of China's Food Policy Evolution}

In China, the choice and evolution of food policy has invariably been compatible with the economy system. The value upheld by decision makers has played a decisive role in food policy evolution (Zhao Deyu, 2010).

(I) The evolution of China's food policy compatible with the economy system

As food policy is determined under the framework of the macroeconomic system, its evolution is consistent with the change of the macroeconomic system. To be specific, with further transformation and development of the economy system, the process of regulation on food has been from absent to strengthened, overall and loose. It is worth noting that the agriculture sector played a leading role in the process of developing the planned economy system. It means the planned economy should firstly find application in the agriculture sector, to provide primary accumulation to industrialization. In carrying forward the socialist market-oriented reform, the reform in grain industry was conspicuously lagging behind other industries, which highlighted the important strategic position that grain holds as a special merchandize closely related to social stability. To sum up, the choice and evolution of China's food policy has always been in accord with the economy system in given period, ready for changing along with the strength that the government uses to control food.

(II) Means used in China's food policy compatible with that used in macro economy.

In different periods, more planning or more market on food control is contingent on the macroeconomic system prevailing in that time. Under planned economy, the means used in macro economy was administrative order where it was more likely to adopt more planning on food regulation, the policy of "state monopoly for purchases and marketing” for instance. At the early period of market economy, the macroeconomic means was a combination of planning and market. In food policy, it was interpreted as the "dual-track" period. With the market economy moving forward, it was more dependent on market instead of planning.

(III) The evolution of China's food policy in implementation represented by change of objects under regulation, methods and strength of regulation.

Different controlled objects and methods used for regulation in different periods need different strength on food regulation. Horizontally, in the same period, regulation on grain production, circulation and consumption was varied. In the early days of new nation, there was hardly regulation on grain. However, during overall regulation period, the regulation on circulation and consumption was more than production. Longitudinally, varied regulation strength in different periods were expressed in non-regulation, strengthened, overall and loose regulations. Take circulation as the object. Under planned economy, it adopted more planning on it, but more market on it under market economy. The regulation on grain circulation had gone from zero to one and loose control. As a result, the integrated policies taking into account the objects, methods and strength demonstrate the trajectory that China's food policy has gone along.

\section{Results and Revelation}

Food policies practiced in different periods were reviewed herein, which can be divided into four 
stages according to regulation strength, non-regulation from 1949 to 1952, strengthened regulation from 1953 to 1957, overall regulation from 1958 to 1978 and loose regulation from 1979 to now. Based on horizontal and vertical comparison of the four stages, it can be seen that the evolution of China's food policy is compatible with our macroeconomic system, and the means applied during the evolution is also consistent with that used in the system. The evolution of China's food policy in implementation is represented by change of objects under regulation, methods and strength of regulation. Adjustment of regulation strength and objects is complementary. How strong the regulation must be reflected in the regulation policies on production, circulation and consumption. In the same period, regulation policies in different sectors were varied with diverse priority; regulation policies on different objects in different stages were also quite different.

Under the background of new food security policy and further promotion of reform and opening up, it is particularly essential to give more freedom to grain sector and carry forward the market-oriented reform. In the area of food production, it should boost grain production and protect land productive capability with safeguarding rural income as the primary objective; in the area of grain consumption, it should ensure the low-income groups to access to grain; in circulation, it should deepen the reform of the grain price formation system, improve the grain circulation management system and promote the market reform of the state-owned grain enterprises.

\section{Acknowledgement}

Foundation Project: This article is the stated achievements of National Natural Science Foundation of China "Policy Research on Domestic Soybean Industry Development under the Background of Import Expansion” (Project No.: 71373116) and China Association for Science and Technology High-end Science and Technology Innovation Think Tank Youth Project "Policy Research on Improving the Technical Efficiency of Grain Circulation Industry of China” (Project No.: DXB-ZKQN-2016-22)

\section{References}

[1] Cai Danchun, Wu Xiaolan. Seek Both Efficiency and Fairness with Market as OrientationAnalysis of 1998 Food Circulation System Reform With Incrementalism [J]. Reform Forum, 2009(2):50-51.

[2] Cao Baoming. Analysis of Market-Oriented Reform of China's Food Circulation [J]. Jiangsu Social Sciences, 1998,23-30.

[3] Historical materials of Contemporary China's Grain Work [M]. Contemporary China's Grain Work Editorial Department of the Ministry of Commerce, 1998.

[4] Contemporary China's Grain Work [M]. China Social Sciences Publishing House, 1998.

[5] Deng Xiaohua. Economic Effect of Grain Circulation System Reform [J]. Issues in Agriculture Economy,2004(5):64-66.

[6] Di Qiang. China's Grain Circulation System Reform and Innovation Based on Safety and Efficiency [D]. Southwestern University of Finance and Economics, 2010.

[7] Liu Ying. Research on the Reform of China's Grain Circulation System under Market Trend [D]. Huazhong Agricultural University, 2006.

[8] Mao Mingchen. Summary of Research on Government Regulation [J]. Management World, 
2007(02).

[9] Wang Dewen, Huang Jikun. Reform of China's Grain Circulation System: Transition and Termination of Dual Track [J]. Reform, 2001(4):99-106.

[10]Wang Shuangzheng. 30 years of Grain Circulation System Reform: Review and Reflection [J]. Economics of Finance and Trade, 2008(11):111-127.

[11]Wu Wentan, Zhou Zhou. Analysis of China's Grain Circulation System Evolution Government Regulation-Based Objective, Means and Performance [J]. Food Economy Research, 2015,1(01):1-9.

[12] Yang Shaozheng. Theoretical Evolution of Government Regulation and Theoretical Hypothesis of China's Economy Transforming Period [J]. Economic System Reform, 2008(03).

[13]Zeng Guoan. Regulation, Government Regulation and Economic Regulation [J]. Economic Review, 2004,(1):93-103.

[14]Zhao Deyu. Concept logic of interpreting food policy evolution: Perspective of Political Economy [J]. Chinese Rural Economy, 2010,26(4): 20-29.

[15]Zhou Zhou, Shi Qi. Multiple Objectives, Internal Contradictions and Reform Cycles-Analysis of China's Grain Policy Evolution Course [J]. Rural Economy, 2017(06):11-18. 